\title{
Evaluation of a Fresh Fruit Distribution Program in an Ethnically Diverse San Francisco High School
}

\author{
Jason M. Nagata, Melvin B. Heyman, and Janet M. Wojcicki \\ Department of Pediatrics, University of California, San Francisco, CA 94143, USA \\ Correspondence should be addressed to Janet M. Wojcicki, wojcicki@gmail.com
}

Received 14 June 2012; Accepted 19 July 2012

Academic Editors: W. Aekplakorn and S. M. Pezzotto

Copyright () 2012 Jason M. Nagata et al. This is an open access article distributed under the Creative Commons Attribution License, which permits unrestricted use, distribution, and reproduction in any medium, provided the original work is properly cited.

\begin{abstract}
Objectives. We evaluated the effects of a Department of Education Fresh Fruit and Vegetable Program (FFVP) on food consumption habits in an inner-city, San Francisco high school. Methods. One intervention high school received a California state grant from the Department of Education to distribute fruit biweekly from fall 2008 to spring 2010 and coordinate associated nutrition education. Students completed 1793 surveys at the intervention school and 778 surveys at a comparison school that assessed fruit, vegetable, fast food and soda consumption habits. Pearson's chi-squared tests were used to compare consumption of foods. Results. At the end of the intervention period, the percentage of students consuming soft drinks once or more per day was significantly lower in the intervention versus comparison school $(3.1 \%$ versus $8.9 \%, P=0.01)$. Consumption of candy once or more per week was also lower in the intervention versus the comparison school in fall 2009 (55.7\% versus $64.0 \%, P=0.01$ ). No significant changes in fruit and vegetable consumption were observed in the intervention or comparison schools. Conclusions. Fruit distribution programs in high schools may decrease high school students' consumption of soft drinks and candy.
\end{abstract}

\section{Introduction}

Rising rates of overweight among school-aged children have been linked to decreases in school-related physical activity, rising consumption of fast foods and soft drinks, poor eating behaviors, and increased television viewing [1-3]. In adults, fruit and vegetable consumption is associated with lower adiposity $[4,5]$, lower energy intake $[6,7]$, and reduced risk of chronic diseases associated with obesity [8]. Among children, fruit and vegetable consumption is associated with lower weight and body mass index [9-11]. Despite these potentially beneficial effects, fruit and vegetable consumption is below recommended levels among children. Recent data from the 2009 Youth Risk Behavior Survey (YRBS) indicated that only $22.3 \%$ of high school students had eaten fruits and vegetables five or more times per day in the previous 7 days $[12,13]$. Meanwhile, 29.2\% of high school students had drunk a bottle, can or glass of nondiet soda daily during the last 7 days [13].

The Fresh Fruit and Vegetable Program (FFVP) is a federal program developed by the US Department of
Agriculture in 2002 in part to increase fruit and vegetable consumption among low-income children and concomitantly address the obesity epidemic [14]. The federal Consolidated Appropriations Act of 2008 (PL 110-161) allocated $\$ 9.9$ million to establish the FFVP in all 50 states and the District of Columbia. In 2008, the Farm Bill increased funding for the program to $\$ 1.2$ billion to support the continued growth of the number of elementary schools participating. California received \$2.5 million in 2008 from the Department of Education, the agency that administers the program in California, to fund students participating in the program at $\$ 50-55$ per student anticipating that by 2011 California would receive $\$ 9$ million for the program. Schools that participate in the program are required to be in the National School Lunch Program and in the School Breakfast Program, and $50 \%$ of the student body needs to be eligible for free or reduced-price meals [14].

As federal funding for the FFVP is expected to increase in coming years, it is important to review the effectiveness of these programs to increase fruit and vegetable intake and the impact on overall dietary intake. Although the FFVP has 
been in place since 2002 in a variety of rural and urban settings, few studies have evaluated the overall impact of the FFVP. Most evaluations have assessed impact on fruit and vegetable intake without reviewing the impact of these programs on overall dietary intake, including fast food or soda consumption. As nutrition education is a necessary part of the FFVP programs and previous studies have suggested an association between fruit and vegetable intake and better health outcomes in children, these types of evaluations are needed.

Previous studies of FFVP have generally found a positive impact of the program on fresh fruit and vegetable intake. A study from 25 schools in Mississippi found that the FFVP increased fruit consumption among 8th and 10th grade students by 0.34 and 0.61 servings per day, respectively, as well as increased the variety of fruits and vegetables tried by students [15]. Similarly, a study evaluating the FFVP at a high school in Houston, Texas [16], found students at the intervention school were more likely to consume fruit, 100\% fruit juice and vegetables five or more times per day in the preceding day than students in the comparison school at the end of the intervention period. In a study of 25 schools in Wisconsin, intervention students reported an increased willingness to try new fruits and vegetables [17]. Moreover, 4th graders at the intervention schools were also more likely to choose a vegetable as a snack instead of chips/candy although these differences were not seen in children in older grades [17].

International studies of fruit distribution programs have also found positive benefits. In Norway, a free fruit distribution program significantly increased students' fruit and vegetable consumption, both during the intervention and at followup three years later $[18,19]$.

The San Francisco Unified School District (SFUSD) has a history of developing progressive district-wide nutrition policies beginning in 2003, which included requiring the elimination of foods that did not meet food minimal federal nutrition standards, setting maximum levels for fat and sugar per item sold, limiting portion sizes, and limiting soft drink sales [20]. San Francisco applied for and received an FFVP grant in 2008 in an effort to improve the nutrition and health at one of San Francisco's largest and most diverse high schools. The grant was written in collaboration between parent volunteers, students who had been active in a pilot program supported by the district's Student Nutrition Services in the prior year, school staff, and teachers. As a part of the FFVP process, an evaluation component was included to assess fruit, vegetable, fast food, and soft drink consumption prior to the start of the program as well at the end of the school year.

\section{Methods}

2.1. Design and School Specifics. This quasi-experimental study used pre- and postintervention surveys to assess fruit and vegetable intake as well fast food, pizza, and soft drink consumption among students at two San Francisco high schools using a food frequency questionnaire. As described above, the intervention school was awarded a California state grant from the Department of Education (Fresh Fruit and Vegetable Program) during 2008-9 and 2009-10, while the other school did not receive a fruit distribution program and served as a comparison school.

During the 2008-9 school year, there were 1,128 students enrolled in the intervention school (54\% Asian American, 23\% Latino, 9\% African American, 5\% white, and 9\% other), with $41 \%$ on the free lunch program and $18 \%$ on the reduced lunch program. The comparison school had an enrollment of 636 in the same time period (40\% Asian American, 20\% Latino, 18\% African American, 6\% white, and 16\% other), with $38 \%$ enrolled in the free lunch program and $20 \%$ in the reduced lunch program.

The Institutional Review Board (Committee on Human Research) at the University of California, San Francisco approved this study in 2008. None of the authors have any financial or other conflicts of interest.

2.2. Intervention. Fresh, seasonal whole fruits were provided to students from fall 2008 to spring 2010 at the intervention school 2 times a week. Before the start of school, in the morning, student volunteers prepared a basket of fruit for each English class or homeroom class in conjunction with school food service staff. English and homeroom classes were chosen as all students participate in at least one of these classes; this distribution plan ensured that each student received fruit on the days it was delivered to the school. Student volunteers subsequently coordinated the delivery of fruit baskets to classrooms with help from school staff and teachers. Fruit was also made available in the after school program daily with support and coordination from the after school staff. Examples of fruits included in the program were apples, pears, peaches, melons, berries, and bananas among others; fruit was locally grown, organic, and whole seasonal fruit.

Nutritional education was also provided at the intervention school including handouts on the nutritional components of distributed fruits described as a "fruit fact". The intervention school also organized biannual health fairs to expose students to nutrition education through games and activities, presentations from local nutrition experts, and tastings of different fruits. A mandatory health education class at the intervention school also incorporated 10 lessons on nutrition and physical activity, featuring the additional information on the fruits served in the FFVP.

2.3. Survey Instrument. Food surveys assessing fruit and vegetable consumption habits were distributed to students at the intervention school in fall 2008 and at both the intervention and comparison schools in spring 2009, fall 2009, and spring 2010. Food frequency surveys were distributed by high school staff to English and homeroom teachers. In the classroom, teachers gave students 10 minutes to complete the survey and students had the option to not participate. Teachers also had the option to not distribute the surveys. On completion, teachers collected the surveys and returned them to the school office where study staff collected them. The survey responses were entered into a spreadsheet for data analysis. 
TABle 1: Demographic characteristics of high school students participating in a fresh fruit program in an intervention school and a comparison school.

\begin{tabular}{|c|c|c|c|c|c|}
\hline \multirow{2}{*}{ Characteristics } & \multicolumn{2}{|c|}{ Intervention school } & \multicolumn{2}{|c|}{ Comparison school } & \multirow{2}{*}{$P^{\mathrm{a}}$} \\
\hline & $n$ & $\%$ & $n$ & $\%$ & \\
\hline \multicolumn{6}{|l|}{ Total } \\
\hline \multicolumn{6}{|l|}{$\operatorname{Sex}^{\mathrm{b}}$} \\
\hline Male & 965 & 54.8 & 390 & 50.9 & \multirow{2}{*}{0.19} \\
\hline Female & 797 & 45.2 & 376 & 49.1 & \\
\hline \multicolumn{6}{|l|}{ Grade } \\
\hline 9 & 710 & 39.6 & 348 & 44.7 & \multirow{4}{*}{$<0.01$} \\
\hline 10 & 477 & 26.6 & 223 & 28.7 & \\
\hline 11 & 248 & 13.8 & 132 & 17.0 & \\
\hline 12 & 358 & 20.0 & 75 & 9.6 & \\
\hline \multicolumn{6}{|l|}{ Fall 2008} \\
\hline \multicolumn{6}{|l|}{ Sex } \\
\hline Male & 360 & 54.0 & NA & NA & \\
\hline Female & 295 & 44.2 & NA & NA & \\
\hline \multicolumn{6}{|l|}{ Grade } \\
\hline 9 & 233 & 34.9 & NA & NA & \\
\hline 10 & 141 & 21.1 & NA & NA & \\
\hline 11 & 106 & 15.9 & NA & NA & \\
\hline 12 & 187 & 28.0 & NA & NA & \\
\hline \multicolumn{6}{|l|}{ Spring 2009} \\
\hline \multicolumn{6}{|l|}{ Sex } \\
\hline Male & 95 & 52.8 & 100 & 51.80 & \multirow{2}{*}{0.90} \\
\hline Female & 85 & 47.2 & 93 & 48.10 & \\
\hline \multicolumn{6}{|l|}{ Grade } \\
\hline 9 & 93 & 50.3 & 96 & 48.70 & \multirow{4}{*}{0.43} \\
\hline 10 & 45 & 24.3 & 43 & 21.80 & \\
\hline 11 & 19 & 10.3 & 16 & 8.10 & \\
\hline 12 & 28 & 15.1 & 42 & 21.30 & \\
\hline \multicolumn{6}{|l|}{ Fall 2009} \\
\hline \multicolumn{6}{|l|}{ Sex } \\
\hline Male & 378 & 54.2 & 168 & 50.0 & \multirow{2}{*}{0.30} \\
\hline Female & 319 & 45.8 & 168 & 50.0 & \\
\hline \multicolumn{6}{|l|}{ Grade } \\
\hline 9 & 286 & 40.4 & 153 & 45.1 & \multirow{4}{*}{$<0.01$} \\
\hline 10 & 197 & 27.8 & 98 & 28.9 & \\
\hline 11 & 121 & 17.1 & 73 & 21.5 & \\
\hline 12 & 104 & 14.7 & 15 & 4.4 & \\
\hline \multicolumn{6}{|l|}{ Spring 2010} \\
\hline Sex & & & & & \\
\hline Male & 132 & 57.4 & 122 & 51.50 & 0.35 \\
\hline Female & 98 & 42.6 & 115 & 48.50 & \\
\hline Grade & & & & & \\
\hline 9 & 98 & 42.1 & 99 & 40.90 & \\
\hline 10 & 94 & 40.3 & 82 & 33.90 & $<0.01$ \\
\hline 11 & 2 & 0.9 & 43 & 17.80 & \\
\hline 12 & 39 & 16.7 & 18 & 7.40 & \\
\hline
\end{tabular}

${ }^{a}$ Pearson's chi-square test.

${ }^{\text {b}}$ Totals may be less than $n$ due to missing data. 
Surveys were anonymous and included demographic questions about sex, age, and grade level in addition to general questions about food consumption. Food consumption questions included the following: how many times in a week do you eat fruit (including oranges, apples, pears, plums, melons, berries, peaches, and other fruits), vegetables (including salad, carrots, tomatoes, squash, broccoli, asparagus, zucchini, potatoes, corn, and other vegetables), fast food (including McDonald's, Burger King, and Wendy's), pizza, soft drinks (including colas and sodas), chips, candies, and other food items. We also assessed the consumption of traditional Mexican/Central American foods such as tacos, tortas and burritos given the relatively high percentage of Latino students enrolled at both schools. Response options were: never, once per month, once every two weeks, and one, two, three, four, five, six, or seven times per week. Students were not surveyed on portion sizes. Study authors (J. M. Wojcicki and M. B. Heyman) were asked by the nutrition committee at the San Francisco high school to design the survey and conduct data analysis as part of the school's overall evaluation process of the FFVP. The comparison school was chosen for its similar sociodemographic profile to the intervention school.

2.4. Statistical Analysis. Consumption of individual fruits and vegetables were summed into total fruit and total vegetable categories and means and standard deviations were calculated. Additionally, food and beverage data was categorized in dichotomous groupings. Fruit and vegetable groupings were based on the 2005 Dietary Guidelines for Americans from the United States Department of Health and Human Services and the Department of Agriculture [21]. The following categories were created: $\geq 1 \mathrm{x} /$ day and $<1 \mathrm{x} /$ day for fruits, $\geq 3 \mathrm{x} /$ week and $<3 \mathrm{x} /$ week for vegetables, $\geq 1 \mathrm{x} /$ week and $<1 \mathrm{x} /$ week for fast food, $\geq 1 \mathrm{x} /$ day and $<1 \mathrm{x} /$ day for soft drinks, and $\geq 1 \mathrm{x} /$ week and $<1 \mathrm{x} /$ week for pizza. Mean consumption of different items was compared using $t$-tests and categorical grouping was compared using chisquared tests. Chi-squared tests were subsequently used to compare consumption of specific food items between the intervention and comparison schools at similar time points. To be included in the analysis, students had to provide full demographic data. Data were analyzed using SPSS for Windows (version 12.0, SPSS Inc., Chicago, IL).

\section{Results}

Surveys from fall 2008 to spring 2010 were returned from 1885 intervention school students and 842 comparison school students. Of these, only students who provided complete demographic information and food consumption data were included (1793 (95.1\%) intervention school and 778 (92.4\%) comparison school students).

Sex did not differ between the intervention and comparison schools (Table 1). In both the intervention and comparison schools, ninth graders had the highest representation of completion of study questionnaire $(39.6 \%$ in the intervention school and $44.7 \%$ in the comparison school).
TABLE 2: Baseline weekly fruit and vegetable consumption data at intervention school in fall 2008.

\begin{tabular}{lcc}
\hline Food & $n^{\mathrm{a}}(\%)$ & Mean \pm SD \\
\hline Fruit $\geq 1$ time/day & & \\
No & $345(52.7 \%)$ & \\
Yes & $310(47.3 \%)$ & $8.97 \pm 8.82$ \\
Total fruit ${ }^{\mathrm{b}}$ & & $2.31 \pm 2.08$ \\
Apple & & $1.72 \pm 2.00$ \\
Melon & & $1.89 \pm 2.08$ \\
Orange & & $1.65 \pm 1.98$ \\
Pear & & $1.63 \pm 1.94$ \\
Plum & & \\
Vegetables $\geq 3$ times/day & \\
No & $597(91.1 \%)$ & \\
Yes & $58(8.9 \%)$ & $9.13 \pm 8.68$ \\
Total vegetables ${ }^{\mathrm{c}}$ & & $0.59 \pm 1.26$ \\
Asparagus & $1.34 \pm 1.70$ \\
Broccoli & $1.26 \pm 1.78$ \\
Carrot & & $1.16 \pm 1.54$ \\
Corn & & $1.52 \pm 1.77$ \\
Potato & & $1.74 \pm 2.01$ \\
Salad & & $0.49 \pm 1.06$ \\
Squash & & $1.46 \pm 2.03$ \\
Tomato & & \\
\hline
\end{tabular}

${ }^{\text {a }}$ Total $n=655$ but categories do not always add up to 655 due to missing data.

${ }^{\mathrm{b}}$ Total fruit consumption based on sum of individual fruit consumption.

'Total vegetable consumption based on sum of individual vegetable consumption.

Overall survey response was highest in the intervention school during fall and then declined during the spring time points.

The high response rate to our first survey at the intervention school (58.1\% of the total school) prior to the beginning of the intervention in fall 2008 provides a detailed snapshot of fruit, vegetable, and fast food consumption in this inner-city population. At this timepoint, $47.3 \%$ of students reported consuming one or more fruits per day over the past seven days with mean weekly consumption of fruits being $8.97 \pm 8.82$ (Table 2). Only $8.9 \%$ of students reported consuming three or more vegetables per day over the past seven days (Table 2).

Intervention school students at baseline also reported consuming fast food $(25.6 \%)$, pizza $(21.2 \%)$, chips $(53.7 \%)$, and candy (55.8\%) one or more times per week (Table 3 ). Fourteen percent of students reported consuming soft drinks one or more times per day for the preceding seven days. Fewer students in the intervention school (3.1\%) consumed soda one or more times per day compared with students in the comparison school (8.9\%) at the end of the study, in spring 2010. Consumption of candy declined in the intervention school $55.7 \%$ eating candy one or more times per week in fall 2009 and 56.3\% in spring 2010), in contrast to the comparison school $(64.0 \%$ and $64.8 \%$, resp.; $P=0.01$ and $P=0.07$ ). 
TABLE 3: Baseline weekly food consumption data at intervention school in fall 2008.

\begin{tabular}{|c|c|c|}
\hline Food & $n^{\mathrm{a}}$ & $\%$ \\
\hline \multicolumn{3}{|c|}{ Fast food $\geq 1$ time/week } \\
\hline No & 483 & 74.4 \\
\hline Yes & 166 & 25.6 \\
\hline \multicolumn{3}{|c|}{ Pizza $\geq 1$ time/week } \\
\hline No & 508 & 78.8 \\
\hline Yes & 137 & 21.2 \\
\hline \multicolumn{3}{|c|}{ Sandwich $\geq 1$ time/week } \\
\hline No & 213 & 33.8 \\
\hline Yes & 418 & 66.2 \\
\hline \multicolumn{3}{|c|}{ Burrito $\geq 1$ time/week } \\
\hline No & 529 & 85.0 \\
\hline Yes & 93 & 15.0 \\
\hline \multicolumn{3}{|c|}{ Taco $\geq 1$ time/week } \\
\hline No & 553 & 86.3 \\
\hline Yes & 88 & 13.7 \\
\hline \multicolumn{3}{|c|}{ Torta $\geq 1$ time/week } \\
\hline No & 572 & 91.1 \\
\hline Yes & 56 & 8.9 \\
\hline \multicolumn{3}{|c|}{ Beans $\geq 1$ time/week } \\
\hline No & 467 & 73.8 \\
\hline Yes & 166 & 26.2 \\
\hline \multicolumn{3}{|c|}{ Salsa $\geq 1$ time/week } \\
\hline No & 496 & 78.1 \\
\hline Yes & 139 & 21.9 \\
\hline \multicolumn{3}{|c|}{ Chips $\geq 1$ time/week } \\
\hline No & 293 & 46.3 \\
\hline Yes & 340 & 53.7 \\
\hline \multicolumn{3}{|c|}{ Candy $\geq 1$ time/week } \\
\hline No & 284 & 44.2 \\
\hline Yes & 358 & 55.8 \\
\hline \multicolumn{3}{|c|}{ Ice cream $\geq 1$ time/week } \\
\hline No & 343 & 54.1 \\
\hline Yes & 291 & 45.9 \\
\hline \multicolumn{3}{|c|}{ Cake $\geq 1$ time/week } \\
\hline No & 365 & 56.7 \\
\hline Yes & 279 & 43.3 \\
\hline \multicolumn{3}{|c|}{ Soft drink $\geq 1$ time/day } \\
\hline No & 561 & 86.4 \\
\hline Yes & 88 & 13.6 \\
\hline \multicolumn{3}{|c|}{ Milk $\geq 1$ time/day } \\
\hline No & 437 & 68.6 \\
\hline Yes & 200 & 31.4 \\
\hline \multicolumn{3}{|c|}{ Juice $\geq 1$ time/day } \\
\hline No & 526 & 83.8 \\
\hline Yes & 102 & 16.2 \\
\hline \multicolumn{3}{|c|}{ Water $\geq 1$ time/day } \\
\hline No & 240 & 37.6 \\
\hline Yes & 399 & 62.4 \\
\hline
\end{tabular}

${ }^{a}$ Total $n=655$ but categories do not always add up to 655 due to missing data.
Fruit consumption did not differ significantly between students at either schools. In spring 2009, 43.9\% of students at the intervention school and $38.9 \%$ of students at the comparison school reported consuming fruit one or more times per day for the past seven days $(P=0.32)$ (Table 4 ). Fruit consumption rates remained similar at the end of the intervention period $(43.5 \%$ at the intervention school and $41.8 \%$ at the comparison school, $P=0.71$ ). In spring 2009 , $10.0 \%$ and $11.9 \%$ of students reported consuming vegetables 3 or more times per day for the past seven days at the intervention and comparison schools, respectively $(P=0.55)$. In fall 2009, the comparison school actually had higher vegetable consumption $(14.0 \%$ with $\geq 3 \mathrm{x} /$ day $)$ while the comparison school had $9.8 \%(P=0.04)$ although in spring 2010 there were again no differences in vegetable consumption between students at the two schools.

Dietary data analyzed as continuous variables versus categorical (results not shown) did not reveal any significant differences.

\section{Discussion}

The results of this evaluation suggest that the fruit distribution pilot program at an inner-city high school may serve to displace soft drinks from students' diets. Norwegian studies have similarly reported that fruit distribution programs decrease intake of soda, candy, and chips among students during a fruit intervention period $[18,19]$. However, the Norwegian school fruit program reported no significant changes in soda, candy, and chips consumption during a three-year followup [18].

The potential replacement of soft drinks by school fruit distribution programs is noteworthy given the rising consumption rates in school-aged children [22]. Moreover, increased consumption of sugar-sweetened beverages has been implicated in rising rates of childhood obesity $[23,24]$.

At baseline, approximately $48 \%$ of students in the intervention school reported eating one or more fruits per day for the last seven days while only $9 \%$ of students reported eating the recommended dietary guidelines of three or more vegetables per day [21]. A study in Texas reported similarly low consumption rates; only $13 \%$ of students reported consuming three or more vegetables per day [16]. In a national survey, rates were also low with only $21 \%$ of high school students consuming five or more servings of fruits and vegetables per day for the preceding seven days [13].

Fruit consumption rates remained similar at the intervention and comparison schools before and after the intervention, despite the fact that fruit was distributed daily at the intervention school. Possible explanations for this lack of change were that students did not consume the fruits that were distributed, students who consumed the fruits did not fill out the surveys in equal numbers with those who did not, or that students did not include the school-distributed fruits in the survey response calculations. In contrast, fresh fruit and vegetable distribution programs in Texas [16] and Mississippi [15] have demonstrated significant increases in fruit consumption among students during the intervention 


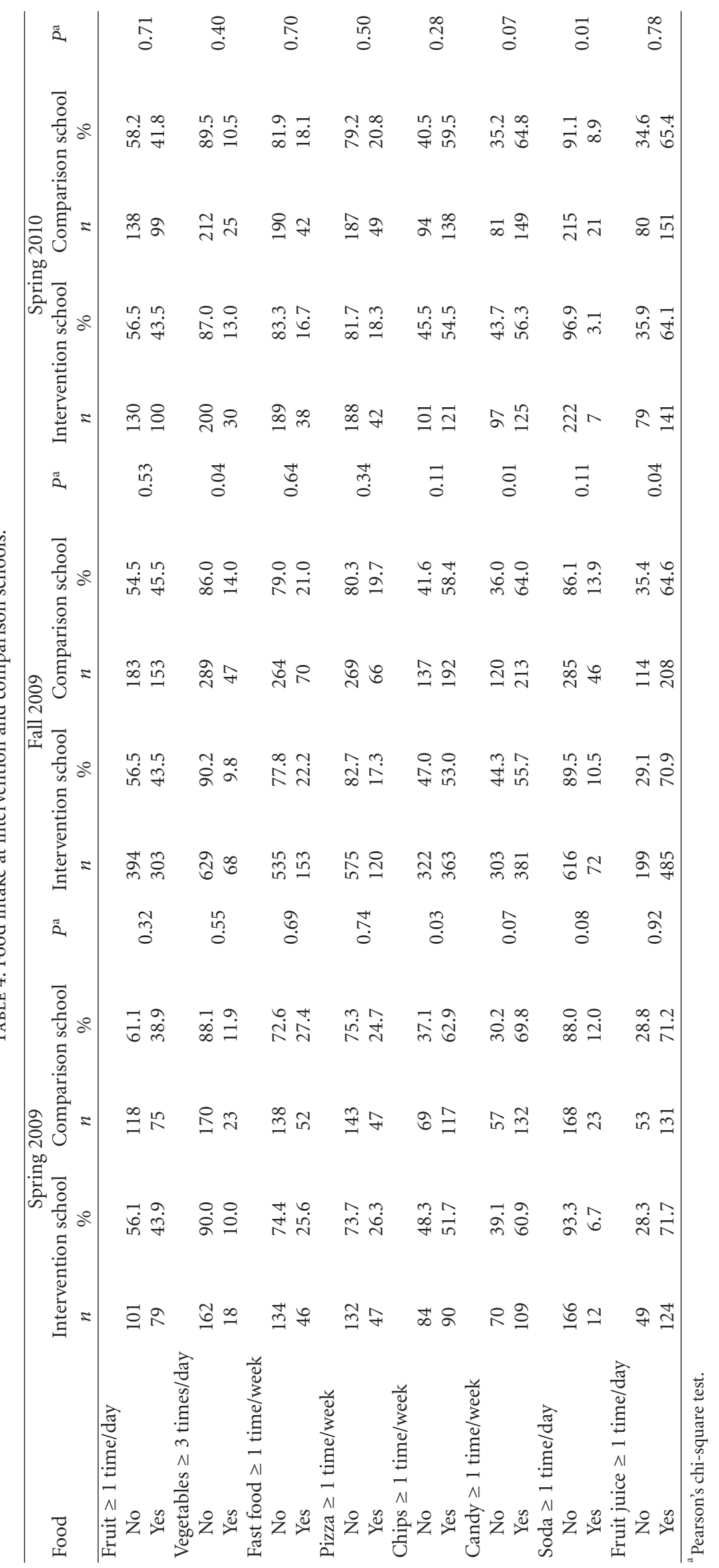


period. No significant changes in vegetable consumption were reported at the intervention or comparison schools, similar to results from other school fruit distribution programs $[15,16]$.

Socioeconomic status has been shown to significantly impact dietary behaviors [25]. Persons living in higherincome neighborhoods report higher levels of fruit and vegetable consumption compared to persons in lower income neighborhoods [26]. Adolescents living in two-parent households report significantly higher fruit and vegetable consumption than adolescents in single-parent households [27]. Fast food restaurants are more prevalent around schools in lower-income neighborhoods than schools in higherincome neighborhoods $[28,29]$. Similarly, soft drinks are more heavily promoted in schools with students from lower socioeconomic backgrounds [30]. Fresh fruit distribution programs may therefore help to ensure that all children have access to healthy foods, and particularly improve the dietary intake of children from lower-income backgrounds.

This study contains several limitations. We did not assess follow-up consumption patterns in individual students; cross-sectional studies were conducted at all time points and children were not tracked. Changes in food consumption over the course of the school year may have been influenced by seasonality or other unknown trends. Student response rates were low, which may limit the generalizability of results. The brief survey used to assess fruit, vegetable, and other food intake over the last seven days may have limited validity when compared with 24-hour dietary recall assessments [31]. Finally, longer-term effects of the program remain to be determined.

This study suggests that fruit distribution programs in high schools may have the effect of displacing students' consumption of soft drinks and fast food. However, further research is required to better understand the mechanisms and effects of fruit distribution programs on students' overall diets and health. Fruit distribution programs may be an important component of future comprehensive school nutritional programs and should be further supported, monitored, and evaluated by schools and researchers.

\section{References}

[1] R. V. Luepker, "How physically active are American children and what can we do about it?" International Journal of Obesity, vol. 23, supplement 2, pp. S12-S17, 1999.

[2] B. M. Davy, K. Harrell, J. Stewart, and D. S. King, "Body weight status, dietary habits, and physical activity levels of middle school-aged children in rural Mississippi," Southern Medical Journal, vol. 97, no. 6, pp. 571-577, 2004.

[3] N. Stettler, "Environmental factors in the etiology of obesity in adolescents," Ethnicity and Disease, vol. 12, no. 1, pp. S1-S1, 2002.

[4] G. Maskarinec, R. Novotny, and K. Tasaki, "Dietary patterns are associated with body mass index in multiethnic women," The Journal of Nutrition, vol. 130, no. 12, pp. 3068-3072, 2000.

[5] B. C. Tohill, J. Seymour, M. Serdula, L. Kettel-Khan, and B. J. Rolls, "What epidemiologic studies tell us about the relationship between fruit and vegetable consumption and body weight," Nutrition Reviews, vol. 62, no. 10, pp. 365-374, 2004.
[6] J. A. Ello-Martin, L. S. Roe, J. H. Ledikwe, A. M. Beach, and B. J. Rolls, "Dietary energy density in the treatment of obesity: a year-long trial comparing 2 weight-loss diets," American Journal of Clinical Nutrition, vol. 85, no. 6, pp. 1465-1477, 2007.

[7] B. J. Rolls, J. A. Ello-Martin, and B. C. Tohill, "What can intervention studies tell us about the relationship between fruit and vegetable consumption and weight management?" Nutrition Reviews, vol. 62, no. 1, pp. 1-17, 2004.

[8] L. Dauchet, P. Amouyel, S. Hercberg, and J. Dallongeville, "Fruit and vegetable consumption and risk of coronary heart disease: a meta-analysis of cohort studies," The Journal of Nutrition, vol. 136, no. 10, pp. 2588-2593, 2006.

[9] K. W. Cullen, T. Baranowski, L. M. Klesges et al., "Anthropometric, parental, and psychosocial correlates of dietary intake of African-American girls," Obesity Research, vol. 12, supplement 9, pp. 20S-31S, 2004.

[10] M. G. Roseman, W. K. Yeung, and J. Nickelsen, "Examination of weight status and dietary behaviors of middle school students in Kentucky," Journal of the American Dietetic Association, vol. 107, no. 7, pp. 1139-1145, 2007.

[11] M. S. St John, M. Durant, P. D. Campagna et al., "Overweight Nova Scotia children and youth: the roles of household income and adherence to Canada's food guide to health eating," Canadian Journal of Public Health, vol. 99, no. 4, pp. 301-306, 2008.

[12] S. M. Krebs-Smith, D. A. Cook, A. F. Subar, L. Cleveland, J. Friday, and L. L. Kahle, "Fruit and vegetable intakes of children and adolescents in the United States," Archives of Pediatrics and Adolescent Medicine, vol. 150, no. 1, pp. 81-86, 1996.

[13] D. K. Eaton, L. Kann, S. Kinchen et al., "Youth risk behavior surveillance-United States, 2009," Morbidity and Mortality Weekly Report, vol. 59, no. 5, pp. 1-142, 2010.

[14] California Department of Education (News Release), State Schools Chief Jack O'Connell Announces Grants to Help Students Eat More Fresh Fruits and Vegetables, 2008.

[15] Centers for Disease Control and Prevention, "Evaluation of a fruit and vegetable distribution program-Mississippi, 200405 school year," Morbidity and Mortality Weekly Report, vol. 55, no. 35, pp. 957-961, 2006.

[16] E. M. Davis, K. W. Cullen, K. B. Watson, M. Konarik, and J. Radcliffe, "A fresh fruit and vegetable program improves high school students' consumption of fresh produce," Journal of the American Dietetic Association, vol. 109, no. 7, pp. 1227-1231, 2009.

[17] E. Jamelske, L. A. Bica, D. J. McCarty, and A. Meinen, "Preliminary findings from an evaluation of the USDA fresh fruit and vegetable program in Wisconsin schools," Wisconsin Medical Journal, vol. 107, no. 5, pp. 225-230, 2008.

[18] E. Bere, M. B. Veierød, O. Skare, and K. I. Klepp, "Free school fruit-sustained effect three years later," International Journal of Behavioral Nutrition and Physical Activity, vol. 4, article 5, 2007.

[19] E. Bere, M. B. Veierød, and K. I. Klepp, "The Norwegian school fruit programme: evaluating paid vs. no-cost subscriptions," Preventive Medicine, vol. 41, no. 2, pp. 463-470, 2005.

[20] J. M. Wojcicki and M. B. Heyman, "Healthier choices and increased participation in a middle school lunch program: effects of nutrition policy changes in San Francisco," American Journal of Public Health, vol. 96, no. 9, pp. 1542-1547, 2006.

[21] United States Department of Health and Human Services and the Department of Agriculture, Dietary Guidelines for Americans, US Government Printing Office, Washington, DC, USA, 2005. 
[22] S. A. French, B. H. Lin, and J. F. Guthrie, "National trends in soft drink consumption among children and adolescents age 6 to 17 years: prevalence, amounts, and sources, 1977/1978 to 1994/1998," Journal of the American Dietetic Association, vol. 103, no. 10, pp. 1326-1331, 2003.

[23] D. S. Ludwig, K. E. Peterson, and S. L. Gortmaker, "Relation between consumption of sugar-sweetened drinks and childhood obesity: a prospective, observational analysis," The Lancet, vol. 357, no. 9255, pp. 505-508, 2001.

[24] World Health Organization, "Diet, nutrition and the prevention of chronic diseases," Report of a Joint WHO/FAO Expert consultation, World Health Organization, Geneva, Switzerland, 2003.

[25] N. Darmon and A. Drewnowski, "Does social class predict diet quality?" American Journal of Clinical Nutrition, vol. 87, no. 5, pp. 1107-1117, 2008.

[26] T. Dubowitz, M. Heron, C. E. Bird et al., "Neighborhood socioeconomic status and fruit and vegetable intake among whites, blacks, and Mexican Americans in the United States," American Journal of Clinical Nutrition, vol. 87, no. 6, pp. 18831891, 2008.

[27] N. D. Riediger, S. Shooshtari, and M. H. Moghadasian, "The influence of sociodemographic factors on patterns of fruit and vegetable consumption in Canadian adolescents," Journal of the American Dietetic Association, vol. 107, no. 9, pp. 1511$1518,2007$.

[28] K. M. Neckerman, M. D. M. Bader, C. A. Richards et al., "Disparities in the food environments of New York City public schools," American Journal of Preventive Medicine, vol. 39, no. 3, pp. 195-202, 2010.

[29] Y. Kestens and M. Daniel, "Social inequalities in food exposure around schools in an urban area," American Journal of Preventive Medicine, vol. 39, no. 1, pp. 33-40, 2010.

[30] L. D. Johnston, J. Delva, and P. M. O’Malley, “Soft drink availability, contracts, and revenues in American secondary schools," American Journal of Preventive Medicine, vol. 33, no. 4, supplement 1, pp. S209-S225, 2007.

[31] A. R. Kristal and J. D. Potter, "Not the time to abandon the food frequency questionnaire: counterpoint," Cancer Epidemiology Biomarkers and Prevention, vol. 15, no. 10, pp. 1759$1760,2006$. 


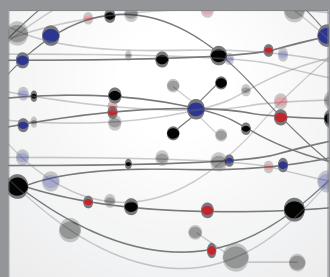

The Scientific World Journal
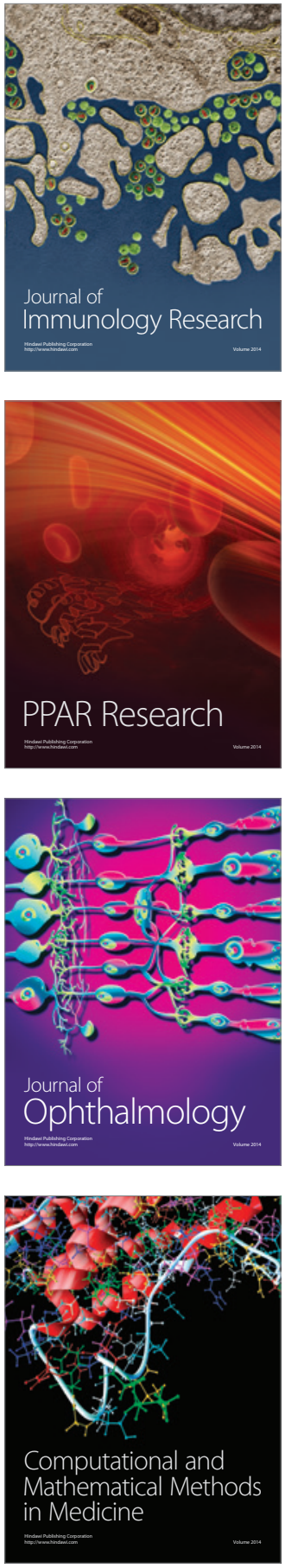

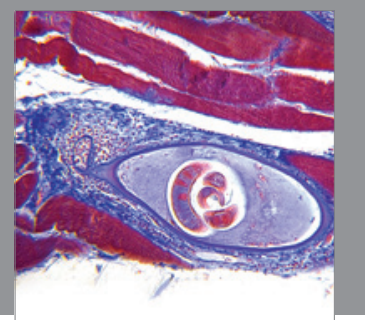

Gastroenterology

Research and Practice
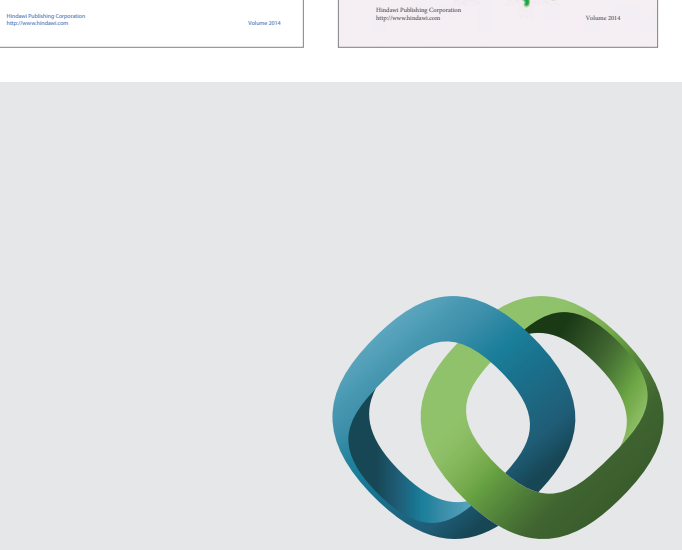

\section{Hindawi}

Submit your manuscripts at

http://www.hindawi.com
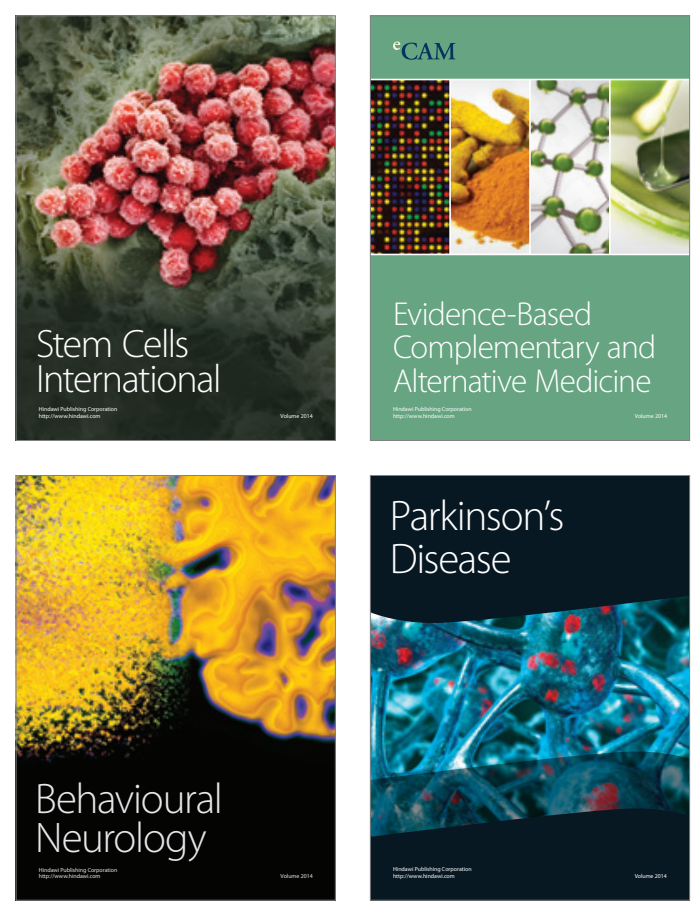

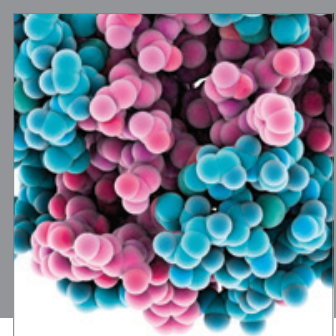

Journal of
Diabetes Research

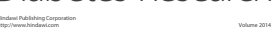

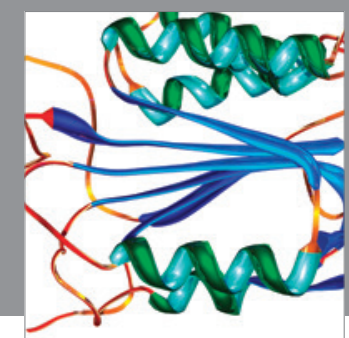

Disease Markers
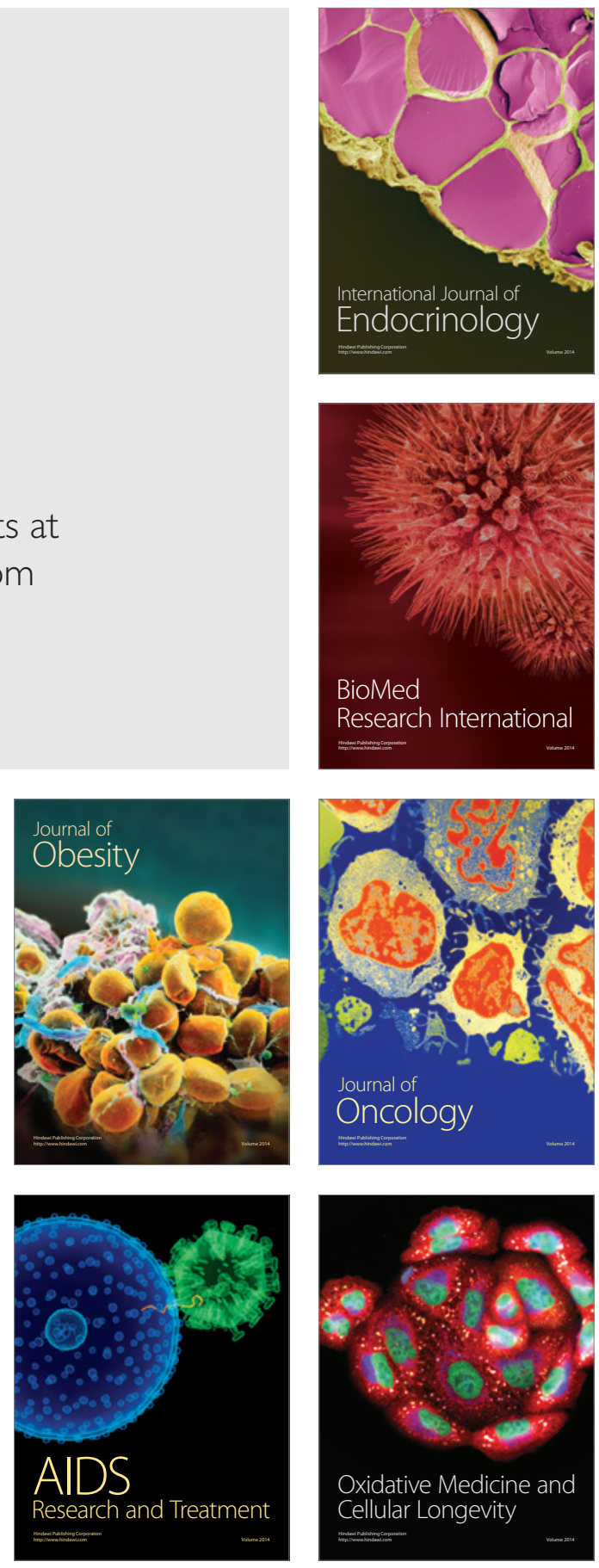